\title{
Entropy effects in conformational distribution and conformationally dependent UV-induced photolysis of serine monomer isolated in solid argon
}

\author{
S. Jarmelo *, R. Fausto \\ Department of Chemistry, University of Coimbra, 3004-535 Coimbra, Portugal
}

Received 6 September 2005; received in revised form 27 September 2005; accepted 27 September 2005

Available online 7 November 2005

\begin{abstract}
Monomeric serine can be trapped in low temperature argon matrices in different conformers, which can be classified in three groups (A, B, C) accordingly to the main intramolecular interaction they exhibit: $\mathbf{A}\left(\mathrm{OH}_{\mathrm{A}} \cdots \mathrm{N}\right.$ hydrogen bond), $\mathbf{B}\left(\mathrm{OH}_{\mathrm{C}} \cdots \mathrm{N}\right)$ and $\mathbf{C}\left(\mathrm{OH}{ }_{\mathrm{A}} \cdots \mathrm{O}=\right)(\mathrm{subscripts} A$ and $\mathrm{C}$ stand for alcohol and carboxylic group, respectively). The $\mathrm{OH}_{\mathrm{C}} \cdots \mathrm{N}$ intramolecular interaction found in B-type conformers is considerably stronger than both the $\mathrm{OH}_{\mathrm{A}} \cdots \mathrm{N}$ and $\mathrm{OH}_{\mathrm{A}} \cdots \mathrm{O}=$ hydrogen bonds, and leads to reduce the abundance of $\mathbf{B}$-type form relatively to $\mathbf{A}$ and $\mathbf{C}$ forms at high temperatures due to entropy effects. When submitted to UV irradiation $(\lambda>200 \mathrm{~nm})$, the main observed photoprocess is decarboxylation, leading to production of $\mathrm{CO}_{2}$ and ethanolamine. A less important photochemical process is also observed, where the compound undergoes decarbonylation, with formation of $\mathrm{CO}, \mathrm{H}_{2} \mathrm{O}$ and acetamide. The two observed photoprocesses were found to be dependent on the conformation assumed by the reactant molecule, with $\mathbf{A}$ - and $\mathbf{C}$-type conformers of serine undergoing decarboxylation and $\mathbf{B}$-type conformers decarbonylation. (C) 2005 Elsevier B.V. All rights reserved.
\end{abstract}

Keywords: Serine; Matrix-isolation infrared spectroscopy; Entropy effect on conformational equilibrium; Conformationally dependent photodecarboxylation

\section{Introduction}

The study of the neutral (non-zwitterionic) form of aminoacids by matrix isolation infrared spectroscopy has been receiving considerable interest in recent years [1-9]. Indeed, this experimental approach has been particularly well succeeded in elucidating many important details of the molecular physics and chemistry of this type of compounds. Some notable examples are (i) the first experimental observation of the third conformer of glycine [1], which until then had successively escaped to detection by other techniques [10], (ii) the first direct observation of conformationally selective aggregation in aminoacids, in the case, $N, N$ dimethylglycine [7], and (iii) the identification of the entropy associated with the intramolecular hydrogen-bonds present in the possible conformers of aminoacids as an important variable to determine their relative gas-phase populations $[8,9]$.

Recently, matrix isolation connected with infrared spectroscopy was also successfully used to investigate the molecular structure, preferred conformations and vibrational

\footnotetext{
* Corresponding author. Tel.: +35 1239852080; fax: + 351239827703.

E-mail address: sjarmelo@qui.uc.pt (S. Jarmelo).
}

spectra of monomeric neutral form of serine [11]. In the gaseous phase, the compound was found to exist in several different conformers, which can be classified in three groups $(\mathbf{A}, \mathbf{B}, \mathbf{C})$ accordingly to the main intramolecular interaction they exhibit: $\mathbf{A}\left(\mathrm{OH}_{\mathrm{A}} \cdots \mathrm{N}\right.$ hydrogen bond $), \mathbf{B}\left(\mathrm{OH}_{\mathrm{C}} \cdots \mathrm{N}\right)$ and $\mathbf{C}$ $\left(\mathrm{OH}_{\mathrm{A}} \cdots \mathrm{O}=\right)$ (throughout this article, in references to the $\mathrm{OH}$ groups, the subscripts $\mathrm{A}$ and $\mathrm{C}$ stand for alcohol and carboxylic group, respectively). Representatives of each of these groups could be trapped in low temperature argon matrices and characterized structurally and spectroscopically [11].

In this study, the conformational equilibrium of serine in the gaseous phase $(T=470 \mathrm{~K})$ was re-investigated by taking into account entropy effects. In addition, the matrix-isolated serine was submitted to UV irradiation $(\lambda>200 \mathrm{~nm})$ and the influence of the conformation of the reactant molecule in determining the preference for two observed reaction channels (decarboxylation and decarbonylation) was investigated.

\section{Experimental and computational details}

Both DL-serine and its D,L $-3,3$-dideuterated ( $>98 \%$ D) isotopologue used in this study were commercial products, obtained from Aldrich and Icon Stable Isotopes, respectively. Matrices were prepared as described elsewhere [11]. The temperatures of the vapor of the compound prior to deposition and of the cold tip of the cryostat were 470 and $10 \mathrm{~K}$, 
respectively. Decomposition of serine was determined by differential scanning calorimetry to start only above $490 \mathrm{~K}$ and, accordingly, no evidence of significant decomposition was found in the registered spectra of the as-deposited matrix. The matrices were irradiated through the outer quartz window of the cryostat, using a high-pressure mercury lamp (HBO200) fitted with a water filter and a cutoff filter transmitting light with $\lambda>200 \mathrm{~nm}$.

All the theoretical calculations were performed using the Gaussian98 program package [12] at the DFT/B3LYP level of theory $[13,14]$, with the extended $6-311++\mathrm{G}(\mathrm{d}, \mathrm{p})$ basis set [15]. The selection of the conformers submitted to investigation took into account the results of our previous extensive conformational study on the same compound [11]. Thermodynamic quantities were obtained as described in [16].

\section{Results and discussion}

A systematic search on the conformational potential energy surface of serine in the neutral form was presented in our previous study on this compound [11]. The DFT/B3LYP/6$311++\mathrm{G}(\mathrm{d}, \mathrm{p})$ theoretical calculations revealed the existence of 61 distinct minima, with the first nine forms (Fig. 1), which differ in energy by less than ca. $7 \mathrm{~kJ} \mathrm{~mol}^{-1}$, being predicted to account to ca. $75 \%$ of the total conformational population at $470 \mathrm{~K}$ (the temperature of the vapor of the compound immediately before deposition) [11]. The estimation of the relative conformational populations made in Ref. [11] assumed nearly similar entropy contributions to the free energy of the conformers, and the experimental analysis of the spectra were shown to be in general good agreement with the theoretical predictions. However, since entropy effects were more recently found to be strongly relevant in determining the gas phase relative conformational populations in phenylalanine [8], a more detailed thermochemical analysis was undertaken in the present study. The results are summarized in Table 1.

As shown in this table, the most stable conformers of serine are representatives of bonding schemes $\mathbf{A}, \mathbf{B}$ and $\mathbf{C}$, whose dominant intramolecular interactions are the $\mathrm{OH}_{\mathrm{A}} \cdots \mathrm{N}$, $\mathrm{OH}_{\mathrm{C}} \cdots \mathrm{N}$ and $\mathrm{OH}_{\mathrm{A}} \cdots \mathrm{O}=$ hydrogen bonds, respectively. B-type conformers (e.g. 2, 3, 5, 8 and 9 ) are stabilized by a strong $\mathrm{OH}_{\mathrm{C}} \cdots \mathrm{N}$ hydrogen bonding interaction, where the combination of donor and acceptor groups is the most favorable among all possible combinations. However, to establish this $\mathrm{H}$-bond, the conformation adopted by the carboxylic group must be the less stable trans configuration (dihedral angle $\mathrm{O}=\mathrm{C}-\mathrm{O}-\mathrm{H}$ is ca. $180^{\circ}$ ) [17-20]. On the other hand, in the $\mathbf{A}$-type conformers (e.g. 1, $\mathbf{4}$ and 6), as well as in the $\mathbf{C}$ form (7), the intramolecular hydrogen bonds are weaker than in $\mathbf{B}$ forms, but the carboxylic group adopts the most stable cis conformation (dihedral angle $\mathrm{O}=\mathrm{C}-\mathrm{O}-\mathrm{H}$ ca. $0^{\circ}$ ) [17-20]. The resulting global minimum is a type A conformer (see Fig. 1).

As it could be expected, entropy only plays a significant role at high temperatures, with the relative conformational energies estimated for low temperatures (either enthalpies, $\Delta H$, or Gibbs free energies, $\Delta G$ ) being essentially equal to the previously reported [11] zero-point corrected relative energies $\left(\Delta E^{\mathrm{ZPVE}}\right.$;
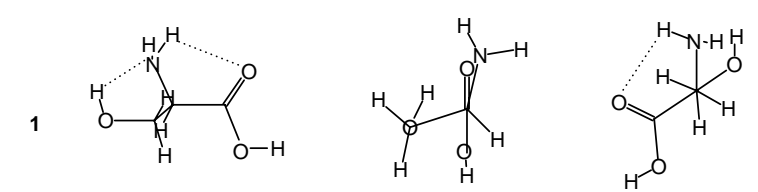

2

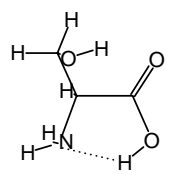

3

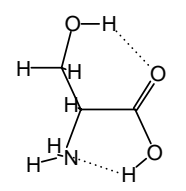

4

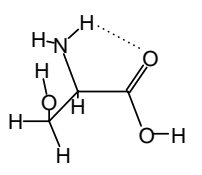

5

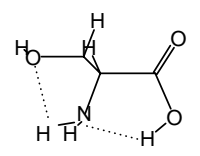

6
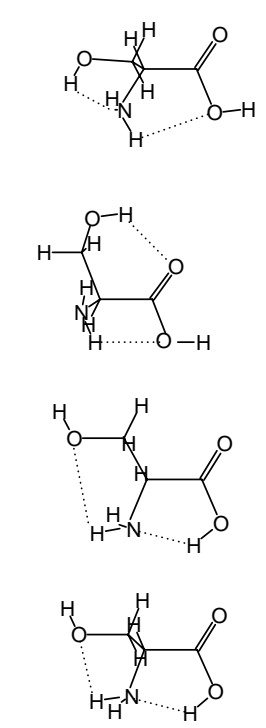
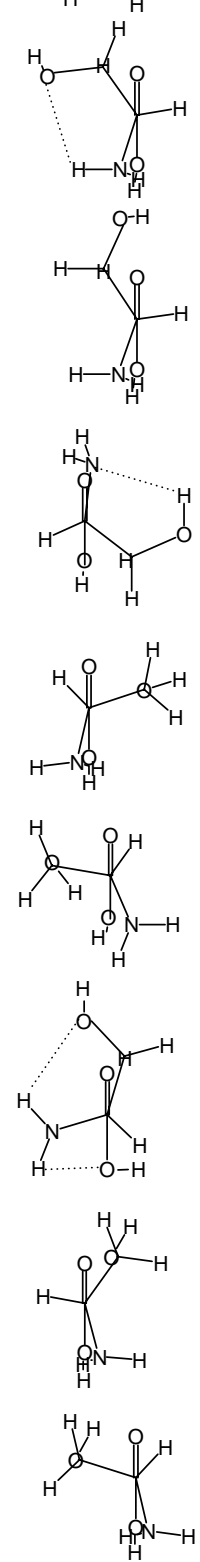
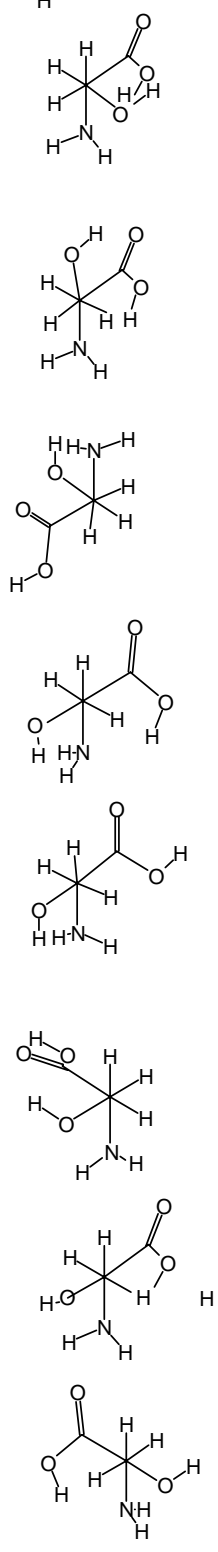

Fig. 1. The nine most stable conformers of serine, drawn in three different perspectives.

see Table 1). At $470 \mathrm{~K}$, the smaller conformational flexibility of the $\mathbf{B}$ conformers, bearing the strongest intramolecular hydrogen bond, justifies the smaller entropy contribution $(T \Delta S)$ to their free energies and, consequently, the increase of the corresponding free energy differences relatively to the most stable conformer. This effect is more important for the lowest energy B-type conformers ( $\mathbf{2}$ and $\mathbf{3}$ ), which correspond to those forms where the intramolecular hydrogen bonds are stronger; in the higher energy $\mathbf{B}$-conformers $(\mathbf{5}, \mathbf{8}, \mathbf{9})$ the entropy contributions practically do not differ from those found in A-type conformers, and the free energy differences at $470 \mathrm{~K}$ are only slightly larger than the zero-point corrected relative 


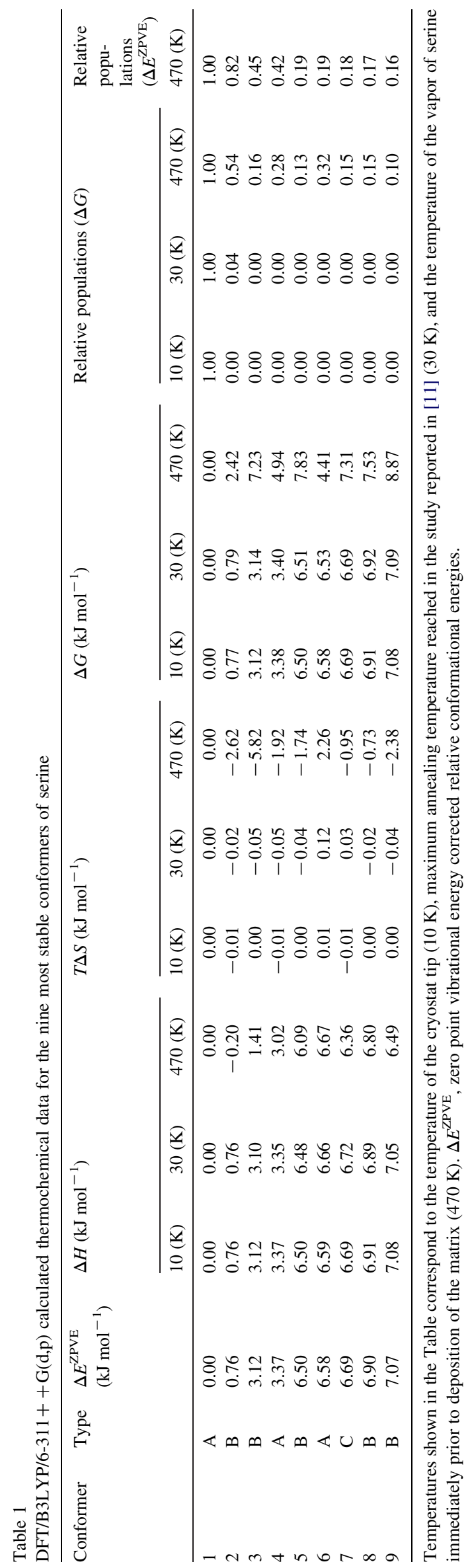

energies. Conformer $\mathbf{C}$ has also a slightly larger entropy contribution to the free energy at $470 \mathrm{~K}$, since in this form, besides the dominant $\mathrm{H}$-bond interaction $\left(\mathrm{OH}_{\mathrm{A}} \cdots \mathrm{O}=\right.$, which could be expected not to differ significantly in energy from that found in the $\mathbf{A}$ conformers, $\left.\mathrm{OH}_{\mathrm{A}} \cdots \mathrm{N}\right)$, two additional interactions take place $\left(\mathrm{NH} \cdots \mathrm{O}_{\mathrm{A}}\right.$ and $\mathrm{NH} \cdots \mathrm{O}_{\mathrm{C}}$; see Fig. 1), contributing to increase the rigidity of the molecule (and, thus, reducing its entropy).

In spite of the above mentioned entropy effects, in serine, contrarily to what was observed in phenylalanine [8], the relative populations of the different conformers are not strongly affected by this variable, in particular in what concerns the general characterization of the equilibrium at $470 \mathrm{~K}$. Indeed, the two most stable conformers are predicted to be the same (conformers $\mathbf{1}$ and $\mathbf{2}$, of $\mathbf{A}$ and $\mathbf{B}$ type, respectively) with or without consideration of entropy effects, and the relative populations of the nine most stable conformers estimated from the calculated free energies or from the zero-point corrected energies do not differ significantly, except that the B-type conformers experiment a general reduction of abundance. This fact justifies the good agreement observed in our previous study [11] between the experimental analysis of the vibrational spectra of the compound and the theoretical predictions based on the relative populations estimated from zero-point corrected energies, i.e. without considering entropy effects. Indeed, the present calculations give further support to the band assignments previously made, in particular with respect to the identification of the specific conformer that is in the origin of the different observed spectral features. In turn, this provides a strong support to the interpretation of the photochemical experiments reported in the present study.

The matrix isolation infrared spectra of serine and 3,3dideutero-serine, in the range $4000-400 \mathrm{~cm}^{-1}$, were discussed in detail previously [11]. Based on the comparison of the experimentally observed frequencies with those obtained theoretically at the DFT/B3LYP/6-311++G(d,p) level for the nine most stable conformers of the two isotopologues, characteristic bands of each family of conformers could then be identified. In this paper, only the $v \mathrm{OH}$ and $\nu \mathrm{C}=\mathrm{O}$ stretching regions will be discussed in detail, which are representative for the goal of showing the dependence of the observed photochemical reactions on the conformation assumed by the reactant molecule.

In the $3700-3100 \mathrm{~cm}^{-1}$ spectral region, besides the $\mathrm{vOH}$ stretching modes, in which our attention is focused, the theoretical calculations predict that all conformers of practical relevance should also give rise to bands due to $\mathrm{vNH}_{2}$ stretching modes. The bands due to $v \mathrm{OH}$ stretching vibrations were predicted to appear at considerably different frequencies in the three groups of conformers (Fig. 2). In conformers belonging to group $\mathbf{A}$, the $v \mathrm{OH}_{\mathrm{C}}$ bands are predicted to occur at slightly higher frequencies than $\mathrm{vOH}_{\mathrm{A}}$, since in these conformers the alcohol group is $\mathrm{H}$-bonded to the amine group. The predicted frequency for $\mathrm{VOH}_{\mathrm{C}}$ is typical of a free cis carboxylic group and is considerably lower than those of the free alcohol groups in all conformers of group $\mathbf{B}$ but conformer $\mathbf{3}$ (where $\mathrm{OH}_{\mathrm{A}}$ is H-bonded to the carbonyl oxygen; see Fig. 1). In conformer 7 

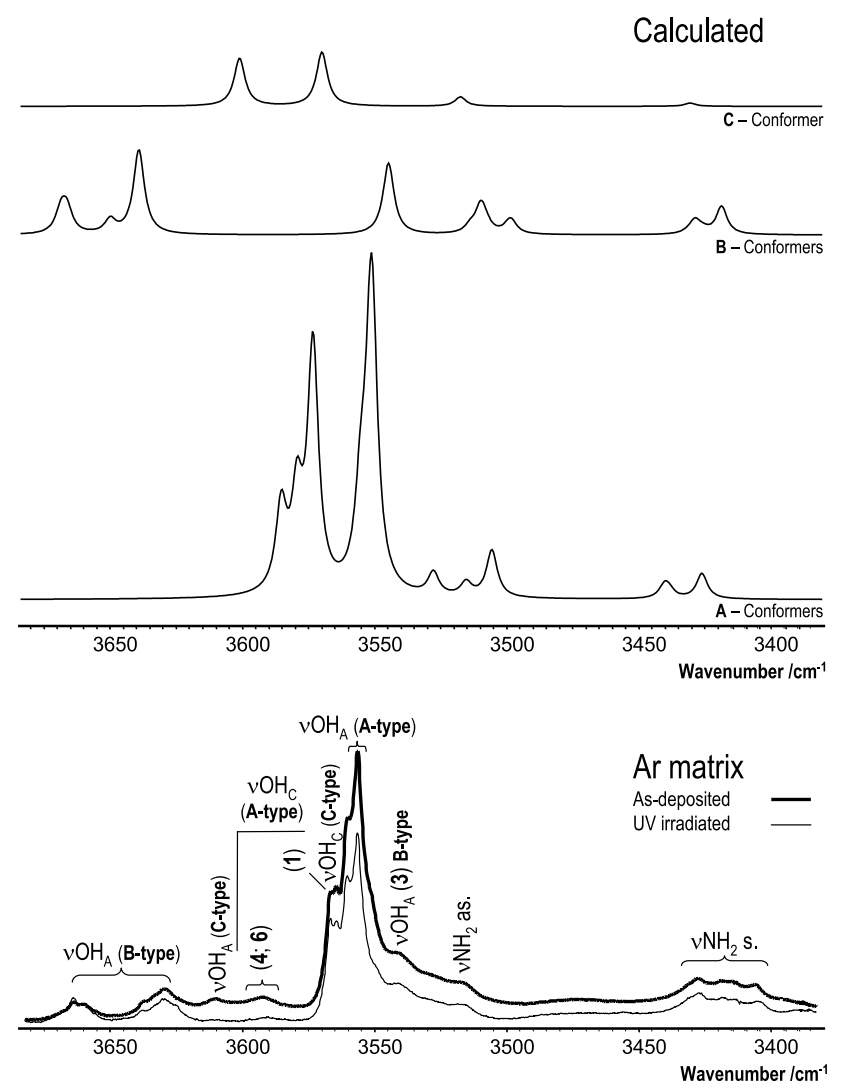

Fig. 2. The $v \mathrm{O}-\mathrm{H}$ and $v \mathrm{NH}_{2}$ stretching region (above $3350 \mathrm{~cm}^{-1}$ ) of the IR spectrum of matrix-isolated serine (Ar matrix) and the spectra calculated at the DFT/B3LYP/6-311++G(d,p) level for the nine experimentally relevant conformers. The calculated spectra for conformers belonging to the same group (A, B or $\mathbf{C}$ ) were added with individual intensities multiplied by the estimated relative populations at $470 \mathrm{~K}$. The $\mathrm{vO}-\mathrm{H}_{\mathrm{C}}$ of the $\mathrm{H}$-bonded B-type conformers are observed as a broad band centered around $3170 \mathrm{~cm}^{-1}$ not shown in this Figure.

(group C), the predicted order of frequencies for the $\mathrm{vOH}_{\mathrm{C}}$ and $\mathrm{VOH}_{\mathrm{A}}$ modes is reversed, since in this case the H-bond involving the alcohol group is established with the carbonyl oxygen atom, that is a weaker $\mathrm{H}$-bond acceptor than the amine nitrogen. In spite of the change in the order of the two $\mathrm{vOH}$ stretching modes in groups $\mathbf{A}$ and $\mathbf{C}$, the general pattern of the spectra for all conformers belonging to these two groups is predicted to be identical (see Fig. 2). In all conformers belonging to group $\mathbf{B}$ (except conformer $\mathbf{3}$ ), where the alcohol group is free, $\nu \mathrm{OH}_{\mathrm{A}}$ is predicted at frequencies above $3600 \mathrm{~cm}^{-1}$. Conformer 3 gives rise to a $\mathrm{vOH}_{\mathrm{A}}$ vibration with a frequency similar to those found in groups $\mathbf{A}$ and $\mathbf{C}$. In all B-type conformers the $\mathrm{vOH}_{\mathrm{C}}$ is predicted at considerably lower frequencies, due to the involvement of the carboxylic group in the strongest $\mathrm{OH}_{\mathrm{C}} \cdots \mathrm{N}$ hydrogen bond. In this spectral region, the experimental spectra nicely fit the theoretical predictions, as shown in Fig. 2, where the assignments are summarized.

The agreement between the calculated and experimentally observed spectra is also very good in the $v \mathrm{C}=\mathrm{O}$ stretching spectral region (Fig. 3). Five main bands due to monomeric serine are observed in between 1850 and $1740 \mathrm{~cm}^{-1}$. The absorptions with maximum at ca. $1720 \mathrm{~cm}^{-1}$, which increased considerably upon annealing, are originated in aggregates,

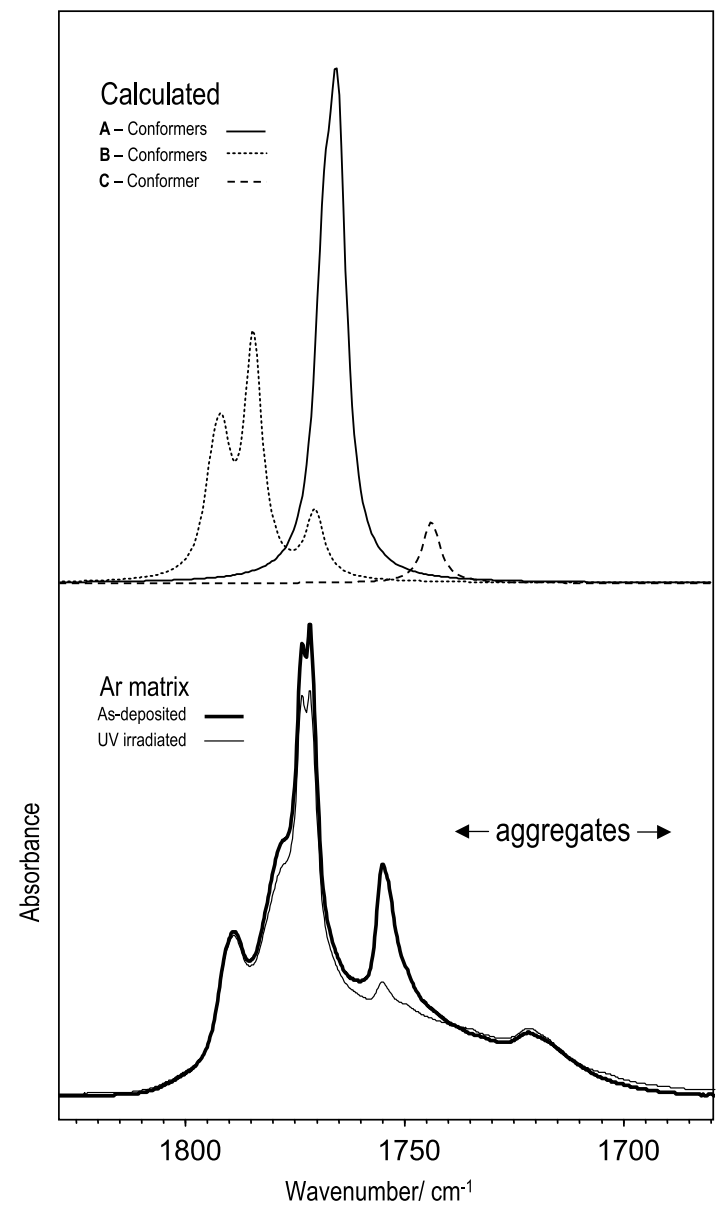

Fig. 3. The $\nu \mathrm{C}=\mathrm{O}$ stretching region of the IR spectrum of matrix-isolated serine (Ar matrix) and the spectra calculated at the DFT/B3LYP/6-311++G(d,p) level for the nine experimentally relevant conformers. The calculated spectra for conformers belonging to the same group (A, B or $\mathbf{C})$ were added with individual intensities multiplied by the estimated relative populations at $470 \mathrm{~K}$.

appearing at similar frequencies observed for aggregates of analogous compounds [21]. B-conformers give rise to $v \mathrm{C}=\mathrm{O}$ bands at higher frequencies than A-conformers, whereas conformer $\mathbf{7}$ (of the $\mathbf{C}$-type) absorbs at a considerably lower frequency than all the other forms. Conformer 3 (B-type) is once again an exception to the regularities found for other B-type conformers, due to the presence in this form of the relatively stronger $\mathrm{OH}_{\mathrm{A}} \cdots \mathrm{O}=\mathrm{H}$-bond, which reduces the frequency of the carbonyl stretching mode, making it similar to those found in the A-group of conformers.

In situ UV irradiation $(\lambda>200 \mathrm{~nm})$ of the matrix led to a general decrease of intensity of the bands ascribed to serine (see Figs. 2 and 3), while bands due to $\mathrm{CO}_{2}$ (around 2340 and $668 \mathrm{~cm}^{-1}$ ), $\mathrm{CO}$ (at ca. $2138 \mathrm{~cm}^{-1}$ ) and $\mathrm{H}_{2} \mathrm{O}$ (both in the 3780 3600 and $1660-1550 \mathrm{~cm}^{-1}$ regions), appeared in the spectra (or increased in intensity ${ }^{1}$ ), testifying the occurrence of both

\footnotetext{
${ }^{1}$ Indeed, in the spectra of the as-deposited samples, small bands due to traces of both $\mathrm{H}_{2} \mathrm{O}$ and $\mathrm{CO}_{2}$, appearing in the matrices as impurities originated mainly from atmospheric gases adsorbed on the surfaces of the inlet devices and vacuum line, could already be observed. These were, however, well-isolated species and do not interfere with the experiment.
} 


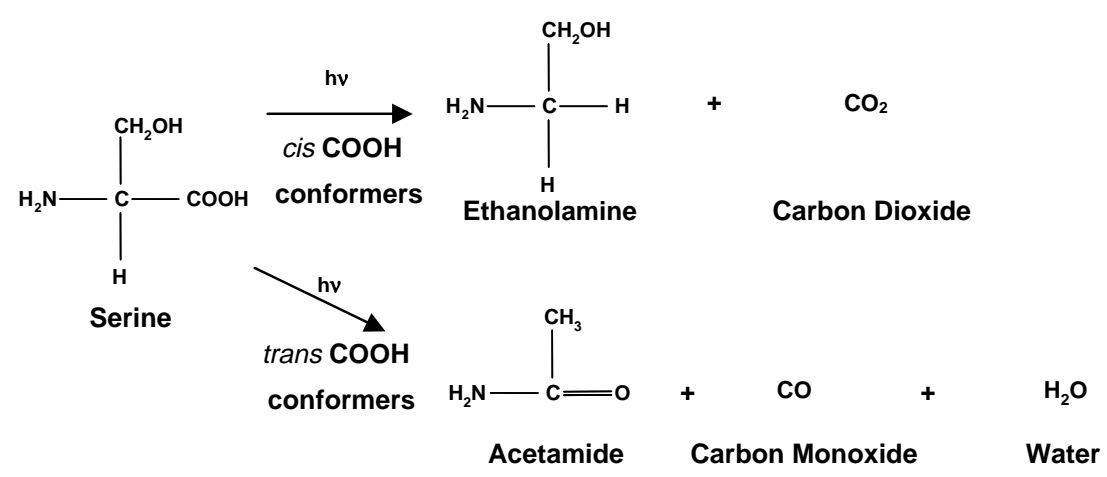

Fig. 4. Unimolecular photodecomposition channels observed in the UV $(\lambda>200 \mathrm{~nm})$ photochemistry of matrix isolated serine.

photodecarboxylation and photodecarbonylation reactions. However, the intensities of the bands ascribed to the different conformers (which are directly related with their relative populations and, then, with the corresponding rates of consumption) showed a different pattern of variation with time of irradiation (see Figs. 2 and 3): conformer 7 (C-type) was found to react more extensively, followed by A-type conformers $(\mathbf{1}, \mathbf{4}$ and $\mathbf{6})$ and then by $\mathbf{B}$-type forms. This is to say that the experimental observations indicate that the photoreactions are strongly dependent on the conformation of the reactant molecule, occurring preferentially for those conformers where the carboxylic group is in the cis conformation and, consequently, not engaged in any $\mathrm{H}$-bond as proton donor.

The formation of $\mathrm{CO}_{2}$, as major product, and of $\mathrm{CO}$ together with $\mathrm{H}_{2} \mathrm{O}$, as minor products, indicates that the dominant observed photoreaction is the decarboxylation of serine. This reaction shall lead to simultaneous production of $\mathrm{CO}_{2}$ and ethanolamine (Fig. 4), while in the less important reaction acetamide shall be produced as primary photoproduct, together with CO.

The observed bands of the photoproduced $\mathrm{CO}_{2}$ and $\mathrm{CO}$ show broad profiles, which strongly differ from those of the monomeric species isolated in argon (Fig. 5) [22,23], clearly indicating that these compounds are interacting with other species produced in the same matrix cage during photolysis of serine. As mentioned above, these species are, with all probability, ethanolamine and acetamide, respectively. However, identification in the spectra of the irradiated matrices of bands originated in these compounds could not be made unequivocally because of the low intensity of their infrared spectra $[24,25]$ and extensive overlap with bands due to the serine (for example, in the high-frequency $\mathrm{vOH}$ stretching region, the most stable conformer of ethanolamine isolated in an argon matrix absorbs at $3555 \mathrm{~cm}^{-1}$ [24], which coincides exactly with the frequency of the most intense group of bands of serine observed in this spectral region). In addition, for ethanolamine, there is also the possibility of photoproduction of different conformers, which leads also to reduce the intensities of bands due to individual conformers, while the total amount of photoproduced acetamide is certainly very low, since this species is produced in the substantially less important reaction channel.
A new band in the spectra of the irradiated matrices was also observed at $2276 \mathrm{~cm}^{-1}$ (Fig. 5). This is a characteristic frequency of the $v \mathrm{~N}=\mathrm{C}=\mathrm{O}$ antisymmetric stretching of the isocyanate moiety [26], and can be due to traces of methylisocyanate $\left(\mathrm{CH}_{3} \mathrm{NCO}\right)$ present in the matrix as result of secondary processes. Note that $\mathrm{CH}_{3} \mathrm{NCO}$ should also absorb around $776 \mathrm{~cm}^{-1}$, and, indeed, the spectral intensity in the $780-765 \mathrm{~cm}^{-1}$ region was also found to increase after irradiation. Nevertheless, the assignment of these weak features to methylisocyanate shall be considered as tentative, since no previous indication was found of direct production of

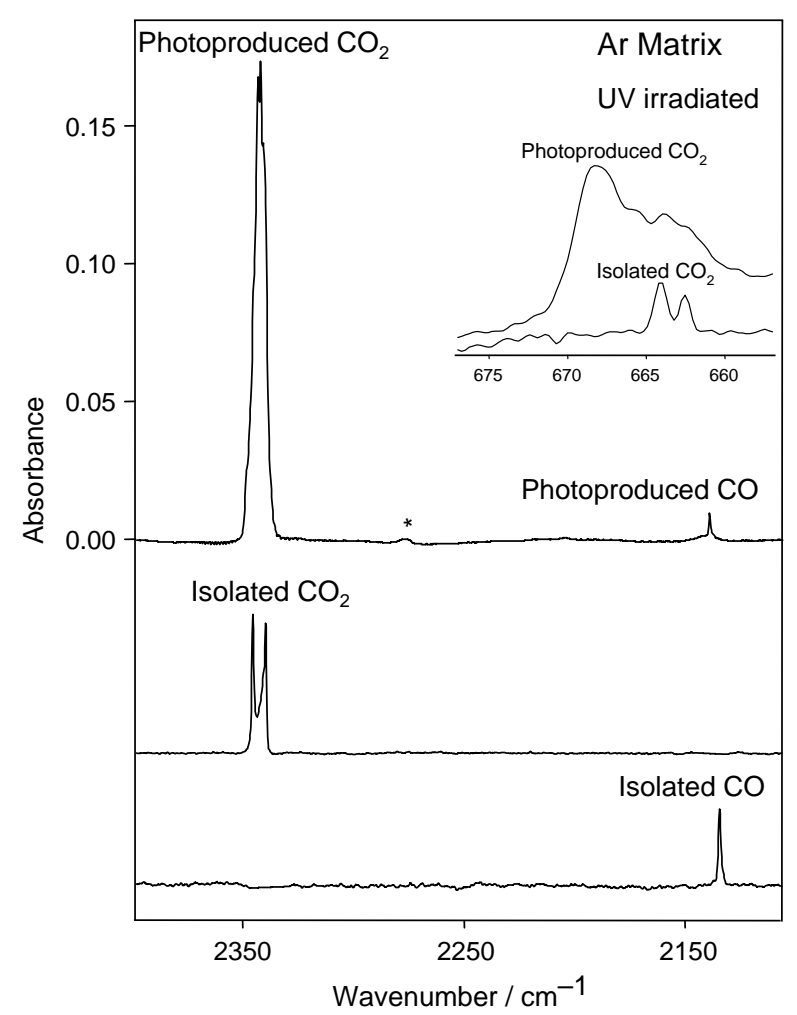

Fig. 5. $\mathrm{CO}_{2}$ bending $\left(670-660 \mathrm{~cm}^{-1}\right)$, and $\mathrm{CO}_{2}$ asymmetric stretching (2360$2320 \mathrm{~cm}^{-1}$ ), CO stretching (ca. $2140 \mathrm{~cm}^{-1}$ ) spectral regions of the serine irradiated matrix and typical spectra of free $\mathrm{CO}_{2}$ and $\mathrm{CO}$ isolated in argon. The origin of the small band marked with an asterisk (at $2276 \mathrm{~cm}^{-1}$ ) is uncertain, but tentatively assigned to methylisocyanate $v \mathrm{NCO}$ antisymmetric stretching (see text) 
this species by UV-photolysis of either ethanolamine of acetamide isolated in matrices [27-30].

The mechanisms of the photolysis processes cannot be unequivocally established on the basis of the experiments here described. However the photochemical reactions shall involve radical intermediates resulting from $\alpha$-cleavages either of the $\mathrm{C}-\mathrm{C}_{\alpha}$ bond or $\mathrm{C}-\mathrm{O}$ bond, as found previously for most of the carboxylic acids that undergo decarboxylation or decarbonylation reactions upon UV irradiation [31-36]. This indicates that the decomposition reactions shall take place mainly on the excited state surfaces rather than in the vibrationally excited ground state. In the case of acetic acid, whose excited states $\left(\mathrm{S}_{1}\right.$ and $T_{1}$ ) surfaces have been extensively studied in relation to photodecomposition dynamics [37], the transition states for the $\mathrm{C}-\mathrm{C}_{\alpha}$ bond cleavage (associated to the decarboxylation reaction) in the $S_{1}$ and $T_{1}$ surfaces were found to have geometries that can be correlated with different conformations of the carboxylic moiety: cis for $S_{1}$ and trans for $T_{1}$ [37]. Assuming that in serine an analogous situation occurs, and taken into consideration that the $\mathrm{T}_{1} \leftarrow \mathrm{S}_{0}$ is a forbidden transition, the decarboxylation reaction in this compound shall then be strongly preferred when started from $\mathbf{C}$ - and A-type conformers, as is supported by the observed different rates of consumption of the three types of conformers of serine.

To test this hypothesis, the amount of $\mathrm{CO}_{2}$ produced was estimated from the intensity of the band at ca. $2340 \mathrm{~cm}^{-1}$, using the calculated intensity for this mode $\left(712 \mathrm{~km} \mathrm{~mol}^{-1}\right)$ as normalizing factor, and compared with the amount of serine in the $\mathbf{A}$ and $\mathbf{C}$ conformations that was consumed (in this case, the decrease in the intensity of the $3580-3500 \mathrm{~cm}^{-1}$ spectral region upon irradiation was considered to make the estimation, together with the relevant calculated intensities and expected abundances of the different $\mathbf{A}$ and $\mathbf{C}$ conformers; this region contains absorptions due to the $\mathrm{vOH}_{\mathrm{A}}$ stretching mode of all $\mathbf{A}$ conformers and to the $\mathrm{vOH}_{\mathrm{C}}$ stretching mode of conformers $\mathbf{1}$ and 7). The obtained values (in arbitrary units) are equal within the experimental error $\left(1.4 \times 10^{-3}\right.$ and $1.5 \times 10^{-3}$, respectively), strongly supporting the idea that the decarboxylation pathway takes place in the $S_{1}$ surface and corresponds essentially to photolysis of serine in the $\mathbf{C}$ and $\mathbf{A}$-type initial conformations.

Very interestingly, analogous calculations made using the $\mathrm{CO}$ band intensity (weighted by the corresponding calculated intensity: $89 \mathrm{~km} \mathrm{~mol}^{-1}$ ) and the relevant data accounting for consumption of B-type conformers (the $\mathrm{vOH}_{\mathrm{C}}$ band in the $3250-3085 \mathrm{~cm}^{-1}$ region, due to all $\mathbf{B}$-type conformers was used in this case, together with the corresponding calculated band intensities and conformer abundances), yield values ( $3 \times$ $10^{-4}$ vs. $7 \times 10^{-4}$ ) which indicate that the amount of $\mathrm{CO}$ produced is similar to the amount of serine in the B-type conformers that were consumed during the photolysis experiments. This indicates that the transition state for the $\alpha$ C-O cleavage in serine's $S_{1}$ surface shall have a nearly trans geometry of the carboxylic group, similar to that exhibited by the $\mathbf{B}$ conformers.

Hence, the results point to the preference by two distinct photolysis reaction channels of monomeric serine isolated in solid argon, which depend on the conformation of the reactant species and develop on the $S_{1}$ surface. The decarboxylation is the preferred path starting from a cis carboxylic group (conformers of A- and C-type), while the decarbonylation path is preferred when the conformation of the carboxylic group of the reactant molecule is trans. The first process is also probably facilitated by the fact that in both $\mathbf{A}$ and $\mathbf{C}$-type conformers the carboxylic moiety is not involved in any intramolecular hydrogen bond as proton donor, while the decarbonylation might also be favoured in conformers $\mathbf{B}$ by the participation of the carboxylic group, as proton donor, in the relatively strong $\mathrm{OH}_{\mathrm{C}} \cdots \mathrm{N}$ intramolecular hydrogen bond, which weakens the $\mathrm{C}-\mathrm{O}$ bond. The relative population of the cis relatively to the trans conformers in matrices also contributes to the observed prevalence of decarboxylation process over the decarbonylation process. The causes leading to the more efficient decarboxylation of the $\mathbf{C}$ conformer relatively to the $\mathbf{A}$ forms are not easy to figure out, but they can be related with the fact that the $\mathbf{C}$ conformer has a weaker $\mathrm{C}-\mathrm{C}_{\alpha}$ bond (also consistent with a lower $\nu \mathrm{C}-\mathrm{C}_{\alpha}$ stretching frequency) than the A-type conformers ( $\mathbf{C}$ conformer: $\mathrm{d}\left(\mathrm{C}-\mathrm{C}_{\alpha}\right)=1.530 \AA$; $v\left(\mathrm{C}-\mathrm{C}_{\alpha}\right)=735 \mathrm{~cm}^{-1} ; \quad$ A conformers: $\mathrm{d}\left(\mathrm{C}-\mathrm{C}_{\alpha}\right)=1.524 \AA$; $v\left(\mathrm{C}-\mathrm{C}_{\alpha}\right): 852 \mathrm{~cm}^{-1}$, average values [11]).

\section{Conclusion}

Monomeric serine can be trapped in low temperature argon matrices in different conformers, which can be classified in three groups $(\mathbf{A}, \mathbf{B}, \mathbf{C})$ accordingly to the main intramolecular interaction they exhibit: $\mathbf{A}\left(\mathrm{OH}_{\mathrm{A}} \cdots \mathrm{N}\right.$ hydrogen bond), $\mathbf{B}$ $\left(\mathrm{OH}_{\mathrm{C}} \cdots \mathrm{N}\right)$ and $\mathbf{C}\left(\mathrm{OH}_{\mathrm{A}} \cdots \mathrm{O}=\right)$. The $\mathrm{OH}_{\mathrm{C}} \cdots \mathrm{N}$ intramolecular interaction found in $\mathbf{B}$-type conformers is considerably stronger than both the $\mathrm{OH}_{\mathrm{A}} \cdots \mathrm{N}$ and $\mathrm{OH}_{\mathrm{A}} \cdots \mathrm{O}=$ hydrogen bonds and leads to reduce their abundance relatively to the other forms at high temperatures due to entropy effects. However, in serine, contrarily to what was recently observed in phenylalanine [8], the general characterization of the equilibrium at $470 \mathrm{~K}$ is not qualitatively affected by this variable.

When submitted to UV irradiation $(\lambda>200 \mathrm{~nm})$, serine decomposes by two different channels in the $\mathrm{S}_{1}$ excited state surface: decarboxylation, leading to production of $\mathrm{CO}_{2}$ and ethanolamine and decarbonylation, with formation of $\mathrm{CO}, \mathrm{H}_{2} \mathrm{O}$ and acetamide. The two observed photoprocesses were found to be dependent on the conformation assumed by the reactant molecule, with A- and C-type conformers undergoing decarboxylation and B-type conformers decarbonylation, a result which is consistent with transition states' geometries of the carboxylic group for the two processes in the $S_{1}$ surface resembling the cis and trans arrangements, respectively.

\section{Acknowledgements}

The authors thank Drs Maciej Nowak and Leszek Lapinski for their useful suggestions and comments. This work was financially supported by 'Fundação para a Ciência e a Tecnologia' (FCT-Projects POCTI/QUI/59019/2004 and POCTI/QUI/58937/2004), Lisbon, and GRICES (Project 00813). S.J. also acknowledges the FCT Grant SFRH/BD/6696/2001. 


\section{References}

[1] I.D. Reva, A.M. Plokhotnichenko, S.G. Stepanian, A.Yu. Ivanov, E.D. Radchenko, G.G. Sheina, Yu.P. Blagoi, Chem. Phys. Lett. 232 (1995) 141.

[2] S.G. Stepanian, I.D. Reva, E.D. Radchenko, M.T.S. Rosado, M.L.T.S. Duarte, R. Fausto, L. Adamowicz, J. Phys. Chem. A 102 (1998) 1041.

[3] D.G. Stepanian, I.D. Reva, E.D. Radchenko, L. Adamowicz, J. Phys. Chem. A 102 (1998) 4623.

[4] A. Gómez-Zavaglia, R. Fausto, Vibrat. Spectrosc. 33 (2003) 105.

[5] R. Ramaekers, J. Pajak, M. Rospenk, G. Maes, Spectrochim. Acta A 61 (2005) 1347.

[6] S.G. Stepanian, I.D. Reva, E.D. Radchenko, L. Adamowicz, J. Phys. Chem. A 105 (2001) 10664.

[7] A. Gómez-Zavaglia, I.D. Reva, R. Fausto, Phys. Chem. Chem. Phys. 5 (2003) 41.

[8] A. Kaczor, I.D. Reva, M. Proniewicz, R. Fausto, J. Phys. Chem. A, (submitted).

[9] B. Lambie, R. Ramaekers, G. Maes, Spectrochim. Acta A 59 (2003) 1387.

[10] K. Iijima, K. Tanaka, S. Onuma, J. Mol. Struct. 246 (1991) 257.

[11] S. Jarmelo, L. Lapinski, M.J. Nowak, P.R. Carey, R. Fausto, J. Phys. Chem. A 109 (2005) 5689.

[12] M.J. Frisch, G.W. Trucks, H.B. Schlegel, G.E. Scuseria, M.A. Robb, J.R. Cheeseman, V.G. Zakrzewski, J.A. Montgomery, Jr., R.E. Stratmann, J.C. Burant, S. Dapprich, J.M. Millam, A.D. Daniels, K.N. Kudin, M.C. Strain, O. Farkas, J. Tomasi, V. Barone, M. Cossi, R. Cammi, B. Mennucci, C. Pomelli, C. Adamo, S. Clifford, J. Ochterski, G.A. Petersson, P.Y. Ayala, Q. Cui, K. Morokuma, D.K. Malick, A.D. Rabuck, K. Raghavachari, J.B. Foresman, J. Cioslowski, J.V. Ortiz, A. Baboul, B.B. Stefanov, A. Liu, G. Liashenko, P. Piskorz, I. Komaromi, R. Gomperts, R.M. Martin, D.J. Fox, T. Keith, M.A. Al-Laham, C.Y. Peng, A. Nanayakkara, M. Challacombe, P.M.W. Gill, B.J. Johnson, W. Chen, M.W. Wong, J.L. Andres, C. Gonzalez, M. Head-Gordon, E.S. Replogle, J.A. Pople, (1998) Gaussian 98, Revision A.9; Gaussian Inc.: Pittsburgh, PA.

[13] A.D. McLean, G.S. Chandler, J. Chem. Phys. 72 (1980) 5639.

[14] A.D. Becke, Phys. Rev. A 38 (1988) 3098.
[15] C.T. Lee, W.T. Yang, R.G. Parr, Phys. Rev. B 37 (1988) 785.

[16] J.W. Ochterski, Thermochemistry in Gaussian, white paper published electronically: (http://Gaussian.com/g_whitepap/thermo.htm).

[17] N.L. Owen, N. Sheppard, Proc. Chem. Soc. London 1963, p. 264

[18] J.E. Piercy, S.V. Subrahmanyan, J. Chem. Phys. 42 (1965) 1475.

[19] J. Bayley, A.M. North, Trans. Faraday Soc. 64 (1968) 1499.

[20] R. Fausto, J.J.C. Teixeira-Dias, J. Mol. Struct. (Theochem). 150 (1987) 381.

[21] S. Jarmelo, R. Fausto, Phys. Chem. Chem. Phys. 4 (2002) 1555.

[22] T. Svensson, B. Nelander, G. Karlström, Chem. Phys. 265 (2001) 323.

[23] H. Abe, H. Takeo, K.M.T. Yamada,, Chem. Phys. Lett. 311 (1999) 153.

[24] C. Cacela, M.L. Duarte, R. Fausto, J. Mol. Struct. $482 / 483$ (1999) 591.

[25] Y. Hase, Spectrochim. Acta A 51 (1995) 2561.

[26] R. Fausto, I.D. Reva, L. Lapinski, Proceedings of the XX IUPAC Symposium on Photochemistry, Granada, Spain, 2004.

[27] F. Duvernay, T. Chiavassa, F. Borget, J.-P. Aycard, J. Phys. Chem. A 109 (2005) 6008.

[28] X.-B. Chen, W.-H. Fnag, D.-C. Fang, J. Am. Chem. Soc. 125 (2003) 9689.

[29] J. Lundell, M. Krajewska, M. Räsänen, J. Mol. Struct. 448 (1998) 221.

[30] J. Lundell, M. Krajewska, M. Räsänen, J. Phys. Chem. A 102 (1998) 6643.

[31] D. Tevault, M. Lin, M. Umstead, R. Smardzewski, Int. J. Chem. Kinet. 11 (1979) 445.

[32] R. Fausto, E.M.S. Maçôas, A. Kulbida, J. Mol. Struct. 480/481 (1999) 83.

[33] E.M.S. Maçôas, L. Khriachtchev, R. Fausto, M. Räsänen, J. Phys. Chem. A 108 (2004) 3380.

[34] S.S. Hunnicutt, L.D. Waits, J.A. Guest, J. Phys. Chem. 95 (1991) 562.

[35] D.R. Peterman, R.G. Daniel, R.J. Horwitz, J.A. Guest, Chem. Phys. Lett. 236 (1995) 564.

[36] P.D. Naik, H.P. Hupadhyaya, A. Kumar, A.V. Sapre, J.P. Mittal, Chem. Phys. Lett. 340 (2001) 116.

[37] W.-H. Fang, R.-Z. Liu, X. Zheng, D. Phillips, J. Org. Chem. 67 (2002) 8407. 